\title{
Electrochemical Reduction of $\mathrm{SiO}_{2}$ Granules to One-Dimen- sional Si Rods Using Ag-Si Eutectic Alloy
}

\author{
Han Ju Lee ${ }^{\dagger}$, Won-Chul Seo ${ }^{\dagger}$, and Taeho Lim* \\ Department of Chemical Engineering, Soongsil University, 369 Sangdo-ro, Dongjak-gu, Seoul 06978, Republic of Korea
}

\begin{abstract}
Producing solar grade silicon using an inexpensive method is a key factor in lowering silicon solar cell costs; the direct electrochemical reduction of $\mathrm{SiO}_{2}$ in molten salt is one of the more promising candidates for manufacturing this silicon. In this study, $\mathrm{SiO}_{2}$ granules were electrochemically reduced in molten $\mathrm{CaCl}_{2}\left(850^{\circ} \mathrm{C}\right)$ using $\mathrm{Ag}$-Si eutectic droplets that catalyze electrochemical reduction and purify the $\mathrm{Si}$ product. When $\mathrm{Ag}$ is used as the working electrode, the Ag-Si eutectic mixture is formed naturally during $\mathrm{SiO}_{2}$ reduction. However, since the $\mathrm{Ag}-\mathrm{Si}$ eutectic droplets are liquid at $850^{\circ} \mathrm{C}$, they are easily lost during the reduction process. To minimize the loss of liquid Ag-Si eutectic droplets, a cylindrical graphite container working electrode was introduced and $\mathrm{Ag}$ was added separately to the working electrode along with the $\mathrm{SiO}_{2}$ granules. The graphite container working electrode successfully prevented the loss of the Ag-Si eutectic droplets during reduction. As a result, the Ag-Si eutectic droplets acted as stable catalysts for the electrochemical reduction of $\mathrm{SiO}_{2}$, thereby producing one-dimensional Si rods through a mechanism similar to that of vapor-liquid-solid growth.
\end{abstract}

Keywords : $\mathrm{SiO}_{2}$, Electrochemical Reduction, $\mathrm{Ag}-\mathrm{Si}$ Eutectic, Molten Salt, $\mathrm{CaCl}_{2}$

Received : 26 June 2020, Accepted : 13 July 2020

\section{Introduction}

In recent years, renewable energy sources, such as sunlight, wind, and flowing water, have attracted considerable attention as alternatives to non-renewable fossil fuels that cause environmental pollution. Among these, solar energy is the most ubiquitous energy source. Photovoltaic (PV) cells that convert solar energy into electricity are made using various materials, such as $\mathrm{Si}, \mathrm{GaAs}, \mathrm{CdTe}$, and perovskites [1-6]. Crystalline Si-based PV cells are the most widely used and account for more than $90 \%$ of the commercial PV cell market due to their high stability, conversion efficiency, and economic feasibility [1]. Though extensive research has been conducted on further increasing the cost efficiency, the cost of solar power generation is still 2-3 times more expensive than that of conventional thermal power generation

†These authors contributed equally.

*E-mail address: taeholim@ssu.ac.kr

DOI: https://doi.org/10.33961/jecst.2020.01151

This is an open-access article distributed under the terms of the Creative Commons Attribution Non-Commercial License (http://creativecommons.org/licenses/by-nc/4.0) , and reproduction in any medium, provided the original work is properly cited. using fossil fuels, hindering the widespread use of solar energy [7]. The high cost of solar power generation is mainly attributed to the high manufacturing cost of Si-based PV cells, with $30-40 \%$ of the cost coming from the production and processing of solar grade Si [8]. Therefore, to lower the cost of solar power generation, it is necessary to develop an inexpensive production process for solar grade $\mathrm{Si}$.

The electrochemical reduction of bulk $\mathrm{SiO}_{2}$ to $\mathrm{Si}$ is considered one possible production alternative. Nohira et al. first reported that bulk $\mathrm{SiO}_{2}$ was electrochemically reduced to $\mathrm{Si}$ in molten $\mathrm{CaCl}_{2}$ at $850^{\circ} \mathrm{C}$ [9]. The electrochemical reduction of $\mathrm{SiO}_{2}$ starts from the three-phase interface, where the insulating material $\left(\mathrm{SiO}_{2}\right)$, conductor (electrode), and electrolyte $\left.\left(\mathrm{molten}^{\mathrm{CaCl}}\right)_{2}\right)$ meet, and propagates as the three-phase interface spreads due to the formation of $\mathrm{Si}$, which is conductive at $850^{\circ} \mathrm{C}$.

$$
\begin{aligned}
& \mathrm{SiO}_{2}(\mathrm{~s})+4 \mathrm{e}- \\
& \rightarrow \mathrm{Si}(\mathrm{s})+2 \mathrm{O}^{2-} \text { (at the three-phase interface) }
\end{aligned}
$$

However, the complete reduction of bulk $\mathrm{SiO}_{2}$ has always been difficult because the propagation of a 
three-phase interface into the bulk $\mathrm{SiO}_{2}$ is not facile. It is difficult for the electrolyte to infiltrate into the bulk material, even though the oxygen extraction from $\mathrm{SiO}_{2}$ during the electrochemical reduction results in porous $\mathrm{Si}[10,11]$. The trapping of oxygen ions $\left(\mathrm{O}^{2-}\right)$, which are the product of the electrochemical reduction of $\mathrm{SiO}_{2}$, in the porous $\mathrm{Si}$ structures also hinders the complete reduction of the bulk $\mathrm{SiO}_{2}[12,13]$.

Therefore, to promote the electrochemical reduction of $\mathrm{SiO}_{2}$, the formation of the three-phase interface must be encouraged. Recently, studies have been conducted on the electrodeposition of a polycrystalline silicon thin film in molten $\mathrm{CaCl}_{2}$ at $850^{\circ} \mathrm{C}$ using $\mathrm{SiO}_{2}$ nanoparticles $[14,15] . \mathrm{SiO}_{2}$ nanoparticles are not soluble; however, they are small enough to be dispersed in molten $\mathrm{CaCl}_{2}$. The dispersed $\mathrm{SiO}_{2}$ nanoparticles are transported by convection and collide with the cathode, resulting in Reaction (1). The small size of the $\mathrm{SiO}_{2}$ nanoparticles facilitates the formation of a three-phase interface and the diffusion of oxygen ions, allowing for a complete reduction of the $\mathrm{SiO}_{2}$ nanoparticles. The use of $\mathrm{Ag}$ as a cathode material has also been reported to enhance the electrochemical reduction of the $\mathrm{SiO}_{2}$ nanoparticles $[16,17]$. During the reduction at $850^{\circ} \mathrm{C}$, the deposited $\mathrm{Si}$ and $\mathrm{Ag}$ form liquid droplets of the $\mathrm{Ag}-\mathrm{Si}$ eutectic mixture that catalyzes the electrochemical reduction of $\mathrm{SiO}_{2}$ and purifies $\mathrm{Si}$. The $\mathrm{Si}$ formation mechanism with Ag-Si eutectic droplets was similar to the vapor-liquid-solid (VLS) growth mechanism involving supersaturation and nucleation at the liquid/solid interface $[18,19]$. However, the loss of the $\mathrm{Ag}-\mathrm{Si}$ eutectic droplets and $\mathrm{Si}$ at the Ag electrode is significant because the unstable interface between the $\mathrm{Ag}$ electrode and $\mathrm{Si}$ is formed by the liquid $\mathrm{Ag}-\mathrm{Si}$ eutectic mixture. At the interface, $\mathrm{Si}$ and the $\mathrm{Ag}-\mathrm{Si}$ eutectic droplets constantly fall off the Ag electrode surface during the electrochemical reduction [16]. This results in the formation of irregular Si dendrites.

In this study, a cylindrical graphite container working electrode was introduced to minimize the loss of the Ag-Si eutectic mixture and Si. The use of this working electrode effectively prevented the loss of the liquid Ag-Si eutectic mixture, and as a result, one-dimensional Si rods could be formed. Furthermore, we conducted a fundamental investigation into the effect of the electrochemical parameters on the electrochemical reduction of $\mathrm{SiO}_{2}$ and proposed an $\mathrm{Si}$ growth mechanism based on it.

\section{Experimental}

Fig. 1 shows the schematic of the electrochemical cell used in this study. The cell consisted of inner and outer quartz tubes with a sealed bottom. The top of the cell was sealed with a stainless-steel cap, and during the experiment Ar gas (99.9\%) was continuously injected into the cell to block the influx of oxygen and moisture. The electrochemical measurements were performed using a potentiostat (PGSTAT302N, Metrohm) with a 3-electrode configuration. The working electrode (WE) was a cylindrical graphite container capable of accommodating $\mathrm{SiO}_{2}$ granules (0.5$10 \mu \mathrm{m}$ in size, Sigma-Aldrich) and Ag (0.05 mmthick foil, $99.9 \%$, Alfa Aesar). The counter electrode (CE) was a graphite rod $(6.15 \mathrm{~mm}$ in diameter, $99.99 \%$, Alfa Aesar). The graphite rod was also used as the pseudo-reference electrode (RE). W wires (1.0 $\mathrm{mm}$ in diameter, $99.95 \%$, Alfa Aesar) were used for the electrode contacts. The electrolyte, $\mathrm{CaCl}_{2}$ molten salt, was placed in an alumina crucible. To prepare the electrolyte, $\mathrm{CaCl}_{2} \cdot 2 \mathrm{H}_{2} \mathrm{O}$ (Daejung Chem-

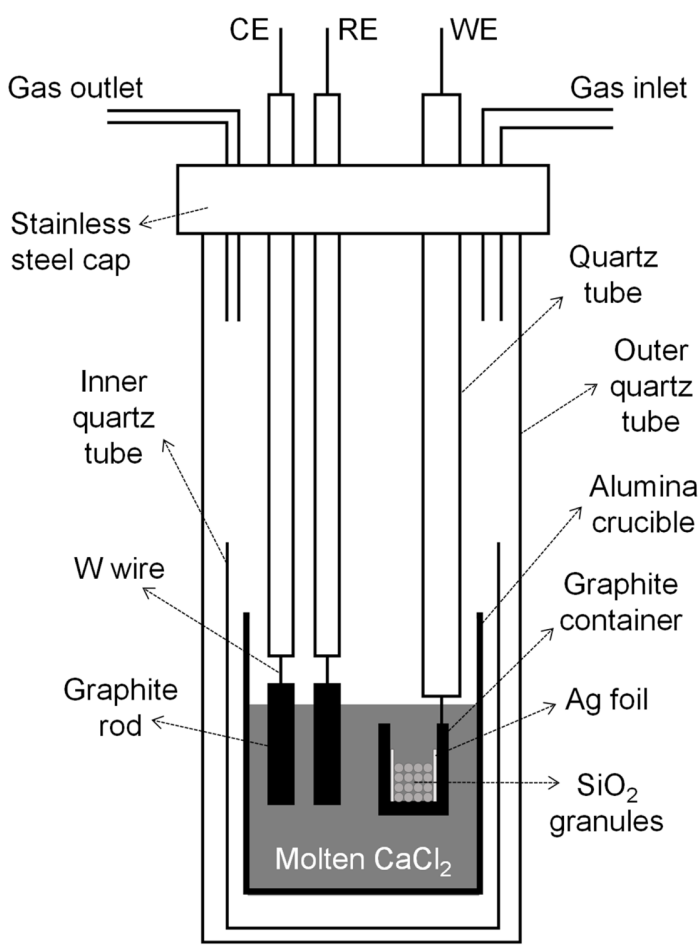

Fig. 1. Schematic diagram of the electrochemical cell used in this study. 
ical and Metals) was dried at $200^{\circ} \mathrm{C}$ in vacuum overnight. Thereafter, $50 \mathrm{~g}$ of the dried $\mathrm{CaCl}_{2}$ was placed in an alumina crucible, which was then loaded into the electrochemical cell. The temperature of the electrochemical cell was raised to $400^{\circ} \mathrm{C}$ at a rate of $6^{\circ} \mathrm{C}$ $\min ^{-1}$ and maintained for $3 \mathrm{~h}$ to remove residual water from the dried $\mathrm{CaCl}_{2}$. Subsequently, the cell temperature was further increased to $850^{\circ} \mathrm{C}$ at a rate of $6^{\circ} \mathrm{C}$ $\mathrm{min}^{-1}$. The graphite container holding the $\mathrm{SiO}_{2}$ granules and $\mathrm{Ag}$ foil was then inserted into the electrochemical cell. The weight of the $\mathrm{SiO}_{2}$ granules was $0.1 \mathrm{~g}$, and the quantity of $\mathrm{Ag}$ foil was added at an $\mathrm{SiO}_{2}$ to Ag weight ratio of 1:1, except for cases where Ag was excluded. The Ag foil was wrapped around the inner wall of the graphite container, touching the working electrode, as shown in Fig. 1. The electrochemical reduction of $\mathrm{SiO}_{2}$ was performed by applying various different potentials to the working electrode. After reduction, the Si samples were sequentially immersed in deionized water for $24 \mathrm{~h}$, followed by submersion in an aqueous solution of $0.1 \mathrm{M} \mathrm{HCl}$ for $14 \mathrm{~h}$ to remove the $\mathrm{CaCl}_{2}$ and other byproducts such as $\mathrm{CaSiO}_{3}$ and $\mathrm{CaO}$. The sample was then dried in a vacuum oven at $50^{\circ} \mathrm{C}$ for $12 \mathrm{~h}$. For the cyclic voltammetry (CV) measurements, a graphite rod and molten $\mathrm{CaCl}_{2}$ containing $1 \mathrm{wt} \%$ $\mathrm{SiO}_{2}$ nanoparticles (10-20 nm in size, SigmaAldrich) were used as the working electrode and electrolyte, respectively. The potential was scanned from 0 to $-2.0 \mathrm{~V}$ (vs. C) at a scan rate of $0.1 \mathrm{~V} \mathrm{~s}^{-1}$.

The shape and composition of the Si sample after the electrochemical reduction of $\mathrm{SiO}_{2}$ was observed using a field emission secondary electron microscope (FE-SEM; GeminiSEM 300, Zeiss) equipped with an energy dispersive spectrometer (EDS; XFlash 6130, Bruker). The crystalline structure of the Si sample was also examined using an X-ray diffractometer (XRD; D2 Phaser, Bruker).

\section{Results and Discussion}

Fig. 2 shows the $\mathrm{CV}$ curve of a graphite electrode in the molten $\mathrm{CaCl}_{2}$ containing $\mathrm{SiO}_{2}$ nanoparticles. The cathodic peak observed at $-1.25 \mathrm{~V}$ was associated with the reduction of $\mathrm{SiO}_{2}$ nanoparticles in contact with the graphite working electrode. The increase in the reduction current at potentials more negative than $-1.5 \mathrm{~V}$ indicated the formation of a $\mathrm{Ca}-$ $\mathrm{Si}$ alloy and/or the reduction of $\mathrm{Ca}$ ions. The anodic

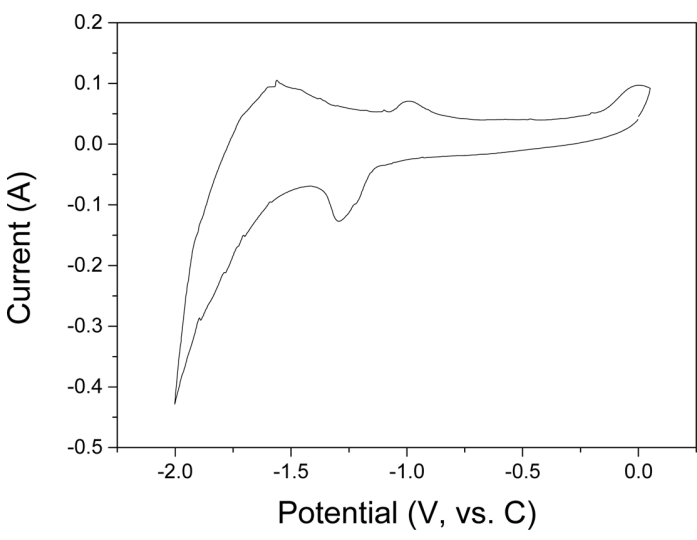

Fig. 2. $\mathrm{CV}$ curve of the graphite electrode in the molten $\mathrm{CaCl}_{2}$ containing $1 \mathrm{wt} \% \mathrm{SiO}_{2}$. The scan rate was $0.1 \mathrm{~V} \mathrm{~s}^{-1}$.

peak observed at $-1.6 \mathrm{~V}$ was related to the oxidation of metallic $\mathrm{Ca}$. It was also observed that the $\mathrm{Si}$, electrodeposited on the graphite electrode during the forward scan, was electrochemically oxidized at $-1.0 \mathrm{~V}$, indicating that the $\mathrm{SiO}_{2}$ nanoparticles in the molten $\mathrm{CaCl}_{2}$ were directly reduced to $\mathrm{Si}$. This result was consistent with previous reports $[14,15]$.

Fig. 3 shows FE-SEM images of the Si samples after the electrochemical reduction of $\mathrm{SiO}_{2}$ with $\mathrm{Ag}$ at different applied potentials when a cylindrical graphite container was used as the working electrode. Since the electrochemical reduction of $\mathrm{SiO}_{2}$ mainly occurred in the potential range between -1.0 and $1.3 \mathrm{~V}$ (Fig. 2), the applied potential was set within this range. In Fig. $3 \mathrm{a}-\mathrm{c}$, when the applied potentials were more positive than $-1.2 \mathrm{~V}$, Si rods were found after the reduction. It was also observed that as the reduction potential decreased, the thickness of the $\mathrm{Si}$ rods decreased and the number density increased. However, the formation of Si rods was hardly observed at $-1.2 \mathrm{~V}$ (Fig. 3d). Fig. 3e shows the FESEM image of the Si sample after the electrochemical reduction of $\mathrm{SiO}_{2}$ without $\mathrm{Ag}$. In this case, particulate $\mathrm{Si}$ was obtained in a form similar to the pristine $\mathrm{SiO}_{2}$ granules shown in Fig. 3f. These results indicated that $\mathrm{Ag}$ induced $\mathrm{Si}$ to grow into a rod-like shape during the electrochemical reduction of $\mathrm{SiO}_{2}$. In addition, most of the formed Si exhibited a onedimensional structure, which was different from the previous reports on the formation of dendritic Si via an Ag-Si eutectic mixture [16,20]. In the course of the electrochemical reduction of $\mathrm{SiO}_{2}$, the Ag reacted 

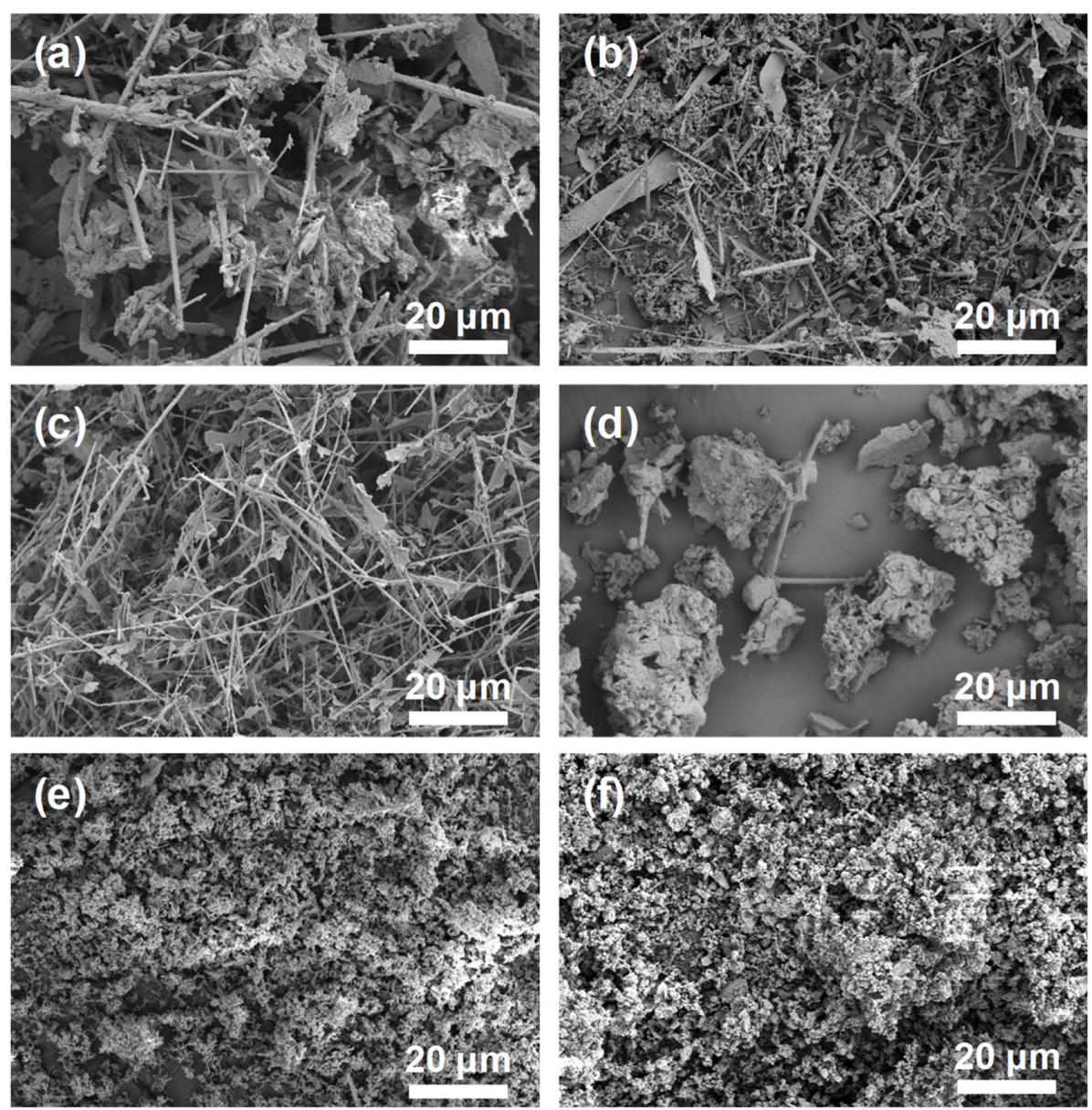

Fig. 3. FE-SEM images of $\mathrm{Si}$ samples after electrochemical reduction of $\mathrm{SiO}_{2}$ granules with $\mathrm{Ag}$ for $3 \mathrm{~h}$ at (a) -1.0, (b) -1.1, (c) -1.15 , and (d) $-1.2 \mathrm{~V}$; (e) the $\mathrm{Si}$ sample after electrochemical reduction of $\mathrm{SiO}_{2}$ without $\mathrm{Ag}$ at $-1.15 \mathrm{~V}$ and (f) the pristine $\mathrm{SiO}_{2}$ granules. The weight ratio of $\mathrm{Ag}$ to $\mathrm{SiO}_{2}$ was 1:1 for Fig. 3a-d.

with the reduced Si to form an Ag-Si eutectic mixture. The eutectic mixture was in a liquid state in the molten $\mathrm{CaCl}_{2}$ bath $\left(850^{\circ} \mathrm{C}\right)$ because the melting point of the $\mathrm{Ag}-\mathrm{Si}$ eutectic mixture was $835^{\circ} \mathrm{C}$ [21]. It is supposed that the liquid eutectic mixture existed as droplets and that these droplets acted as the catalytic liquid alloy for the $\mathrm{SiO}_{2}$ reduction. During the continuous electrochemical reduction, Si nucleated and grew via these droplets to form rod-shaped $\mathrm{Si}$, which followed a mechanism similar to the VLS growth $[18,19]$. If the loss and formation of Ag-Si eutectic droplets was repeated during this process, randomly oriented Ag dendrites may have been formed. Therefore, it was concluded that the use of a graphite container as the working electrode effectively prevented the loss of the Ag-Si eutectic mixture during the elec- trochemical reduction of $\mathrm{SiO}_{2}$. A decrease in the thickness of the Si rod and an increase in the number density due to a decrease in the reduction potential might be related to the Si nucleation. The high overpotential for the $\mathrm{SiO}_{2}$ reduction would have induced the formation of high-density Si nuclei, resulting in thinner Si rods in greater quantities. However, as shown in Fig. 3d, when the applied potential was more negative than $-1.2 \mathrm{~V}$, the formation of Si rods was rarely observed because side reactions, such as $\mathrm{Ca}$ ion reduction and $\mathrm{Ca}-\mathrm{Si}$ alloy formation, were dominant.

Fig. 4a shows EDS elemental mapping results of the Si sample after the electrochemical reduction of $\mathrm{SiO}_{2}$ with $\mathrm{Ag}$ at $-1.15 \mathrm{~V}$. After the reduction, Si rods were clearly observed. The rods in the FE-SEM 

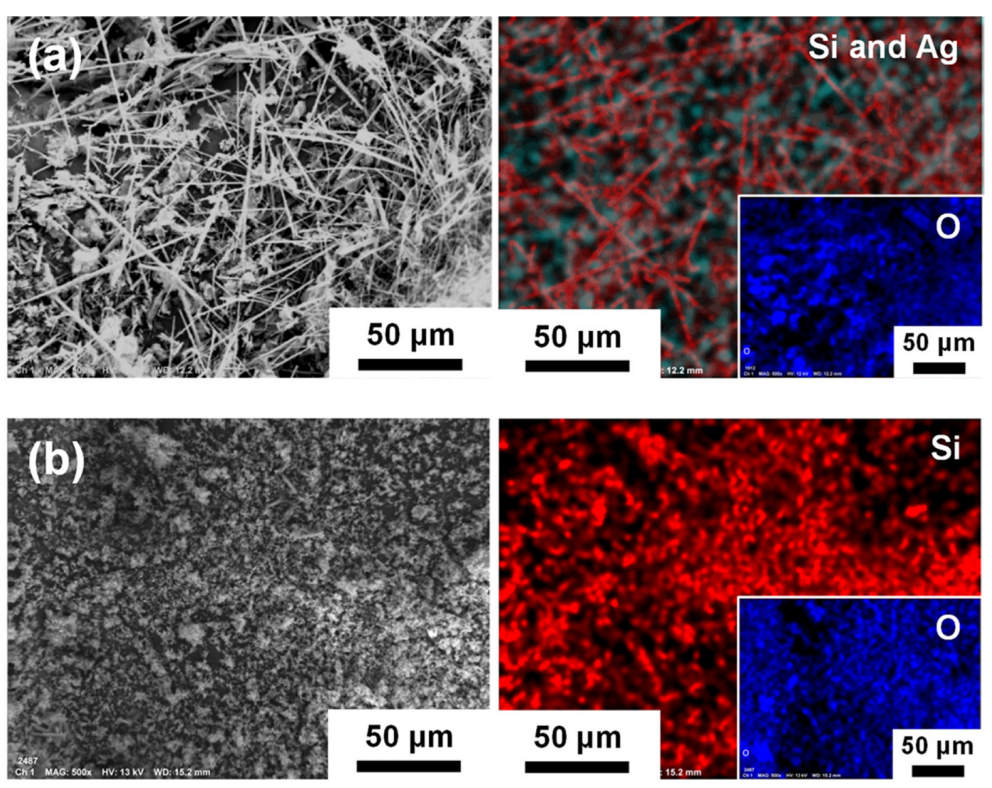

Fig. 4. FE-SEM and EDS elemental mapping images of $\mathrm{Si}$ samples after the electrochemical reduction of $\mathrm{SiO}_{2}$ (a) with and (b) without $\mathrm{Ag}$. The electrochemical reduction was performed at $-1.15 \mathrm{~V}$ for $3 \mathrm{~h}$ and the weight ratio of $\mathrm{Ag}$ to $\mathrm{SiO}_{2}$ was 1:1 for Fig. 4a. The light cyan color in the elemental map of Fig. 4 a represents Ag.

image exactly matched the rod shape shown in the $\mathrm{Si}$ elemental mapping (red). However, no rod shapes were observed in the O elemental mapping (blue), indicating that the rod was mainly composed of Si. There were also unreduced $\mathrm{SiO}_{2}$ granules, which were identified from the places where the elemental maps of Si and $\mathrm{O}$ matched. Ag-Si eutectic droplets were also observed, as shown in the overlap between the elemental mapping of $\mathrm{Ag}$ (cyan) and Si. The Si sample after the electrochemical reduction of $\mathrm{SiO}_{2}$ without Ag is shown in Fig. 4b. The reduced Si particles were mixed with unreduced $\mathrm{SiO}_{2}$ granules, and the two could not be distinguished in the $\mathrm{Si}$ and $\mathrm{O}$ elemental maps.

The growth of the Si rods was monitored over the reduction period. Fig. 5a shows FE-SEM images of the Si rods after different periods of electrochemical reduction. After $30 \mathrm{~min}$ of reduction, only a small quantity of Si rods was observed, and the rest of the $\mathrm{Si}$ was mostly in the form of $\mathrm{SiO}_{2}$ granules. During this period, Ag-Si eutectic formation prevailed over Si rod formation. The number density of Si rods was then increased dramatically with reduction time: the number densities of Si rods were $2.1 \times 10^{2} \mathrm{~cm}^{-2}, 3.3 \times$ $10^{3} \mathrm{~cm}^{-2}$, and $1.0 \times 10^{7} \mathrm{~cm}^{-2}$ after $1 \mathrm{~h}, 2 \mathrm{~h}$, and $3 \mathrm{~h}$ of reduction, respectively. As the reduction time increased, smaller, thinner Si rods were formed, which were newly nucleated and grew on new Ag-Si eutectic droplets that formed during the reduction process. Fig. 5b shows the current-time curves obtained during the electrochemical reduction of $\mathrm{SiO}_{2}$ at $-1.15 \mathrm{~V}$. The reduction current increased by more than two times when $\mathrm{Ag}$ was added. In general, $\mathrm{SiO}_{2}$ reduction begins at the three-phase interface where the $\mathrm{SiO}_{2}$ granules, molten $\mathrm{CaCl}_{2}$, and conductors are in contact, and the reduction propagates along with the newly formed three-phase interface due to the formation of conductive $\mathrm{Si}$ [22]. Therefore, the reduction current is highly dependent on the formation of a three-phase interface. In the absence of $\mathrm{Ag}$, the formation of a three-phase interface within an $\mathrm{SiO}_{2}$ granule was limited as electrochemical reduction progressed. However, in the presence of Ag, droplets of the conductive Ag-Si eutectic mixture naturally formed during the reduction, which enlarged the three-phase interface. The expansion of the three-phase interface by the Ag-Si eutectic mixture increased the reduction current. The observation of the Si rod growth also corresponded with the current-time curve obtained during the electrochemical 
reduction of $\mathrm{SiO}_{2}$ with $\mathrm{Ag}$. The reduction current steadily decreased with the reduction time up to

(a)

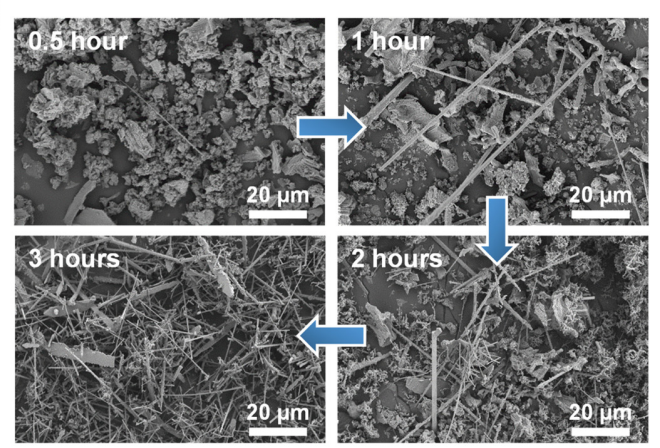

(b)

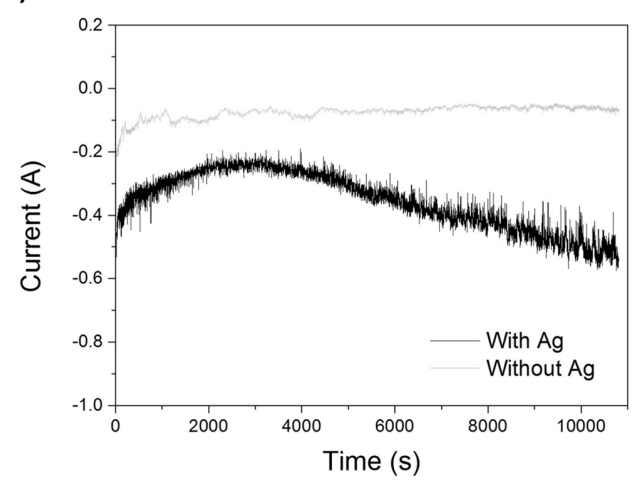

Fig. 5. (a) FE-SEM images of $\mathrm{Si}$ samples depending on the electrochemical reduction time of $\mathrm{SiO}_{2}$ with $\mathrm{Ag}$ at $-1.15 \mathrm{~V}$ and (b) current-time curves recorded during electrochemical reduction of $\mathrm{SiO}_{2}$ at $-1.15 \mathrm{~V}$ for $3 \mathrm{~h}$. The weight ratio of $\mathrm{Ag}$ to $\mathrm{SiO}_{2}$ was 1:1 for the electrochemical reduction of $\mathrm{SiO}_{2}$ with $\mathrm{Ag}$. approximately 2,500 $\mathrm{s}$. It is supposed that during this time period, the formation of the Ag-Si eutectic mixture dominated. Subsequently, as the number of $\mathrm{Si}$ rods increased rapidly, the three-phase interface became large and the reduction current increased again after 2,500 s.

Fig. 6 shows XRD patterns of Si samples after the electrochemical reduction of $\mathrm{SiO}_{2}$ with $\mathrm{Ag}$. The crystalline peaks of Si located at 28.4, 47.2, 56.1, 69.0, and $76.3^{\circ}$, which correspond to $\mathrm{Si}(111), \operatorname{Si}(220)$, $\mathrm{Si}(311), \mathrm{Si}(400)$, and $\mathrm{Si}(331)$, respectively, were observed after the electrochemical reduction. The peak intensity of these peaks increased with the reduction time, while the peaks associated with $\mathrm{SiO}_{2}$

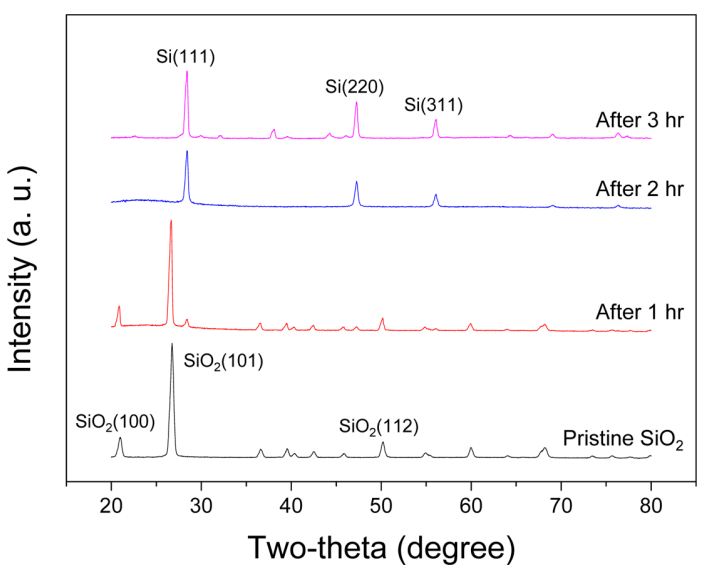

Fig. 6. XRD patterns of $\mathrm{Si}$ samples after the electrochemical reduction of $\mathrm{SiO}_{2}$ with $\mathrm{Ag}$ at $-1.15 \mathrm{~V}$. The weight ratio of $\mathrm{Ag}$ to $\mathrm{SiO}_{2}$ was $1: 1$.
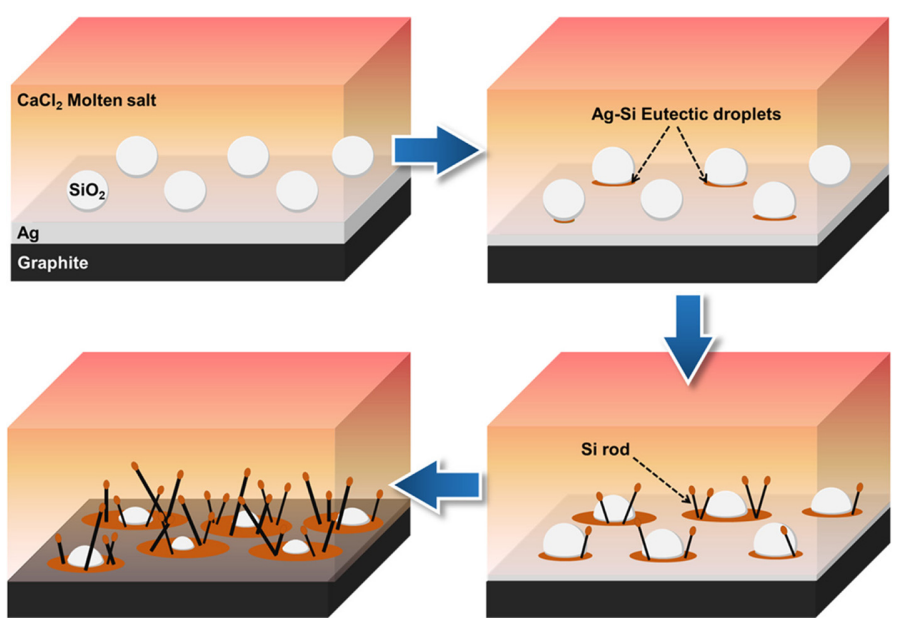

Fig. 7. The schematic diagram of the estimated Si rod growth mechanism. 
decreased, indicating that $\mathrm{SiO}_{2}$ was reduced to $\mathrm{Si}$. In addition, we assumed that the formation of Si nuclei with random orientations on the Ag-Si eutectic droplets during the reduction resulted in polycrystalline $\mathrm{Si}$ rods.

Fig. 7 illustrates the estimated mechanism of Si rod growth during the electrochemical reduction of $\mathrm{SiO}_{2}$ with $\mathrm{Ag}$. Once the reduction started, $\mathrm{SiO}_{2}$ was reduced to $\mathrm{Si}$ at the three-phase interface where $\mathrm{Ag}$, $\mathrm{SiO}_{2}$, and molten $\mathrm{CaCl}_{2}$ met. The $\mathrm{Si}$ then reacted with $\mathrm{Ag}$ to form an $\mathrm{Ag}-\mathrm{Si}$ eutectic droplet. Upon continuous reduction, the $\mathrm{Si}$ became supersaturated in the $\mathrm{Ag}$-Si eutectic droplets, then nucleated and grew into a rod-like shape, following a growth path similar to the VLS mechanism. During reduction, Ag-Si eutectic droplet formation, Si nucleation, and Si rod growth occurred simultaneously to form Si rods of various thicknesses and lengths.

\section{Conclusions}

The electrochemical reduction of $\mathrm{SiO}_{2}$ with $\mathrm{Ag}$ was performed in molten $\mathrm{CaCl}_{2}$ using a cylindrical graphite container as the working electrode. The graphite container working electrode effectively prevented the loss of the Ag-Si eutectic mixture during the electrochemical reduction, thereby expanding the three-phase interface, which increased the reduction current. Moreover, since the Ag-Si eutectic droplets were relatively well-preserved, they successfully acted as catalysts for the formation of one-dimensional Si rods.

\section{Acknowledgement}

This work was supported by the Soongsil University Research Fund (New Professor Support Research) of 2016.

\section{References}

[1] C. Battaglia, A. Cuevas and S. de Wolf, Energy Environ. Sci., 2016, 9, 1552-1576.

[2] E. D. Kosten, J. H. Atwater, J. Parsons, A. Polman and H. A. Atwater, Light Sci. Appl., 2013, 2(1), e45.

[3] H. P. Mahabaduge, W. L. Rance, J. M. Burst, M. O. Reese, D. M. Meysing, C. A. Wolden, J. Li, J. D. Beach, T. A. Gessert, W. K. Metzger, S. Garner and T. M. Barnes, Appl. Phys. Lett., 2015, 106(13), 133501.

[4] N.G. Park, Mater. Materials Today, 2015, 18(2), 65-72.

[5] M. Aliaghayee, H.G. Fard and A. Zandi, J. Electrochem. Sci. Technol., 2016, 7(3), 218-227.

[6] S. Nam, T.K. Vu, D.T. Le and I. Oh, J. Electrochem. Sci. Technol., 2018, 9(2), 118-125.

[7] K. Hansen, Energy Strateg. Rev., 2019, 24, 68-82.

[8] R. Knoblauch, D. Boing, W. L. Weingaertner, K. Wegener, F. Kuster and F. A. Xavier, Wear, 2018, 414, $50-58$.

[9] T. Nohira, K. Yasuda, and Y. Ito, Nat. Mater, 2003, 2(6), 397-401.

[10] W. Xiao, X. Jin, Y. Deng, D. Wang, X. Hu and G. Z. Chen, ChemPhysChem, 2006, 7(8), 1750-1758.

[11] W. Xiao, D. H. Wang, Chem. Soc. Rev., 2014, 43(10), 3215-3228.

[12] X. Yang, K. Yasuda, T. Nohira, R. Hagiwara and T. Homma, J. Electrochem. Soc., 2014, 161(7), D3116

[13] W. Xiao, X. B. Jin and G. Z. Chen, J. Mater. Chem. A, 2013, 1(35), 10243-10250.

[14] S. K. Cho, F. R. F. Fan, A. J. Bard, Electrochim. Acta, 2012, 65, 57-63.

[15] J. Zhao, H. Y. Yin, T. H. Lim, H. W. Xie, H. Y. Hsu, F. Forouzan, and A. J. Bard, J. Electrochem. Soc., 2016, 163(9), D506-D514.

[16] S. K. Cho, F. R. F. Fan, A. J. Bard, Angew. Chem. Int. Ed., 2012, 124(51), 12912-12916.

[17] B. Bokhonov and M. Korchagin, J. Alloy Compd., 2002, 335(1-2), 149-156.

[18] M. Song, Y. T. Zhang, J. Chun, S. Y. Hu, M. Tang and D. S. Li, Nanoscale, 2020, 12(14), 7538-7543.

[19] E. I. Givargizov, J. Cryst. Growth, 1975, 20-30.

[20] S. Fang, H. Wang, J. Y. Yang, B. Yu and S. Lu, Faraday Discuss., 2016, 190, 433-449.

[21] R. W. Olesinski, A. B. Gokhale and G. J. Abbaschian, Bulletin of Alloy Phase Diagrams, 1989, 10(6), 635640.

[22] W. Xiao, X. Jin, Y. Deng, D. Wang and G. Z. Chen, J. Electroanal. Chem., 2010, 639(1-2), 130-140. 